Journal of Accident and Emergency Medicine 1994

$11,45-47$

\title{
The effect of audit and feedback on data recording in the accident and emergency department
}

\author{
J.M.HANSON, G.JOHNSON \& M.J.CLANCY
}

Departments of Accident and Emergency Medicine, St James's University Hospital Leeds, West Yorkshire and Pinderfields Hospital, Wakefield, Yorkshire

\section{SUMMARY}

Thirteen newly appointed senior house officers (SHOs) at two hospitals were assessed in the recording of two variables: Glasgow Coma Scale (GCS) and diagnostic coding at Hospital A, and GCS at Hospital B. At Hospitals A and B baseline recordings of these variables were established. Active feedback (in the form of data presentation and discussion) was given at 6 and 11 weeks and a final 4-week audit was performed on GCS recordings at 20 weeks.

Analysis of GCS recordings of head injuries at Hospitals $A$ and $B$ showed an increase from baseline values of $162 / 401(40 \%)$ to $336 / 420(80 \%)$ after feedback 1 , and after feedback 2 recordings increased to $379 / 429(88 \%)$. This was maintained in the last 4-week audit which showed recordings of 220/244 (90\%).

Further analysis of Hospital A's data showed the SHOs recorded diagnostic coding in 1335/4406 $(30 \%)$ of cases. After feedback 1 , recordings increased to $2550 / 3327(77 \%)$. After feedback 2 there was no change in recording $2712 / 3530(77 \%)$.

Active feedback improves data recording. The first feedback has a greater impact than the second. Two feedbacks produce a sustained effect in 6 months.

Key words: accident and emergency department, audit, feedback.

\section{INTRODUCTION}

Correspondence:

Miss J.M. Hanson, Senior Registrar, Accident and Emergency Department, Hope Hospital, Stott Lane, Salford. Manchester M6 8HD
Medical audit is the systematic critical analysis of the quality of medical care and its resulting outcome, the aim being to improve the effectiveness and efficiency of medical care. ${ }^{1}$ For audit to influence practice, feedback would seem necessary in order to complete the audit loop. ${ }^{2,3}$ This study was performed in order to assess the impact of active feedback, in the presence of peers, on the sub- sequent performance of Accident and Emergency (A\&E) SHOs.

\section{MATERIALS AND METHODS}

Thirteen newly appointed A\&E SHOs were studied in Hospitals A and B (9 SHOs in Hospital A and 4 SHOs in Hospital B). During the first week of their appointment all were asked to record the GCS score for those patients with head injury as their presenting complaint on the A\&E card. At Hospital $A$ the SHOs were also requested to record diagnostic coding in all patients: coding numbers were noted on the back of the A\&E card which was otherwise blank for history and examination. The standard practice required was to record GCS and diagnostic coding on all patients $(100 \%)$ in each study group. The feedback given was active feedback in the form of presentation of individual data and group discussion. The same study design was used in both hospitals. All notes relating to the patient study groups were retrieved by the reception staff and reviewed. The frequency of recording of each item was calculated manually for each $\mathrm{SHO}$ at each hospital by the authors, during the first 6 weeks. During week 6 the SHOs were given feedback (feedback 1) regarding their perfomance. Feedback 2 was given after 11 weeks after a further 5-week audit. Data recording was audited for a further 5 weeks up to week 16 . Diagnostic coding was not audited any further, however, GCS recordings in head injuries were audited for a further 4 weeks between weeks 20 and 24, after a 4-week period of no audit (weeks 16-20). During this audit period (weeks 20-24) the SHOs were unaware that they were being audited. This was to determine whether the improvement was the result of feedback alone or was because the SHOs knew that they were being audited. The study was completed in the 6 months that the SHOs were in the departments. 


\section{Statistics}

The data from Hospitals A and B was analysed using the Mann-U-Whitney statistics test for nonparametric data.

\section{RESULTS}

When analysing the recording of GCS in head injuries at hospitals $A$ and $B$ the recordings increased from baseline values of $162 / 401$ (40\%, range $0-96 \%)$ to values of $336 / 420(80 \%$, range 19-100\%) after feedback 1 and after feedback 2 to values of $379 / 429$ ( $88 \%$, range $40-100 \%)$. This was maintained in the last 4-week audit at 220/244 (90\%, range $80-100 \%$ ).

Further analysis of Hospital A's data showed the SHOs recorded diagnostic coding in 1335/4406 (30\%, range $8-61 \%$ ) of cases. After feedback 1 recordings increased to $2550 / 3327$ (77\%, range $56-86 \% ; P<0.008)$. After feedback 2 there was no change in recording, $2712 / 3530(77 \%$, range $60-88 \% ; P>0.25)$. Figure 1 shows the individual $\mathrm{SHO}$ data collected at Hospital A for GCS recordings in head injuries. There was a significant increase in recording of GCS after feedback $1(P<0.008)$, and a further improvement after feedback $2(P<0.01)$. After a 4-week period of no audit, GCS was reaudited for 4 weeks and recordings were maintained $(P=0.28)$. Figure 2 shows the individual SHO data collected at Hospital A for diagnostic coding recording in all patients: initially diagnostic coding was recorded poorly. There was a siginificant improvement in recording after feedback $1(P<0.008)$, and no further improvement after feedback $2(P>0.25)$. Figure 3 shows the GCS recordings of individual SHOs at Hospital B: again initially GCS was recorded

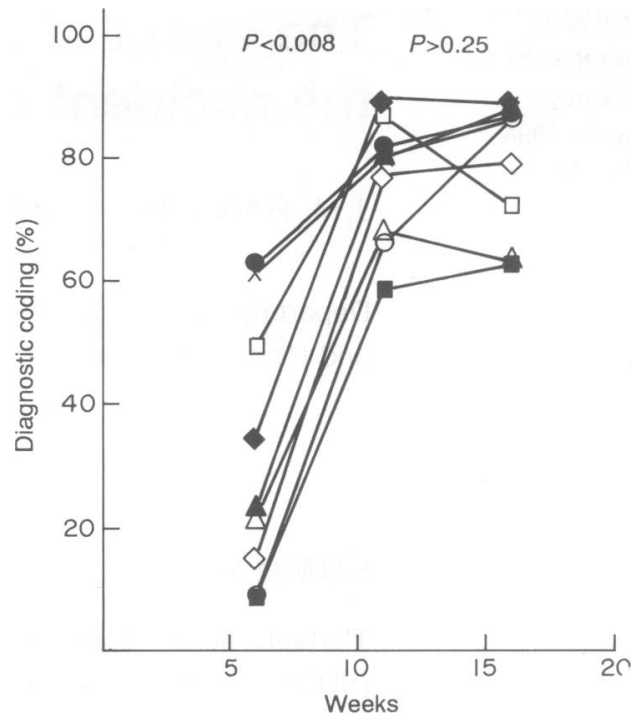

Fig. 2. Graph showing the effect of feedback on each $\mathrm{SHO}$ performance in recording diagnostic coding in all patients who attended the A\&E department at Hospital A.

poorly. After feedback 1 the recordings improved significantly $(P<0.03)$. After feedback 2 there was no further improvement $(P>0.65)$. This improvement was maintained in the last 4-week audit $(P=1.0)$.

\section{DISCUSSION}

There have been over 60 articles on audit where feedback has been implemented and the effect of feedback observed. Only five appear specific to A\&E departments. ${ }^{4-8}$ In this particular study the importance of active feedback, in improving $\mathrm{SHO}$ recording of relevant data in A\&E notes has been assessed. It has shown that GCS and diagnostic coding were recorded poorly in the hospitals involved in the study and that recordings improved signifi-

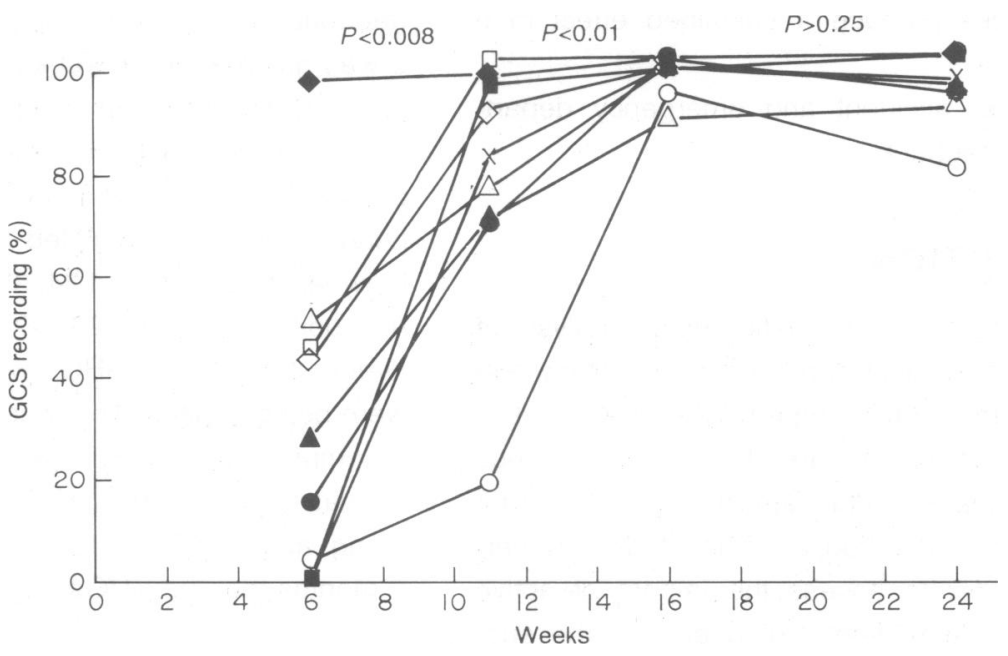

Fig. 1. Graph showing the effect of feedback on each $\mathrm{SHO}$ performance in recording GCS in all head injury patients who attended the A\&E department in Hospital A. 
Effect of audit and feedback on data recording

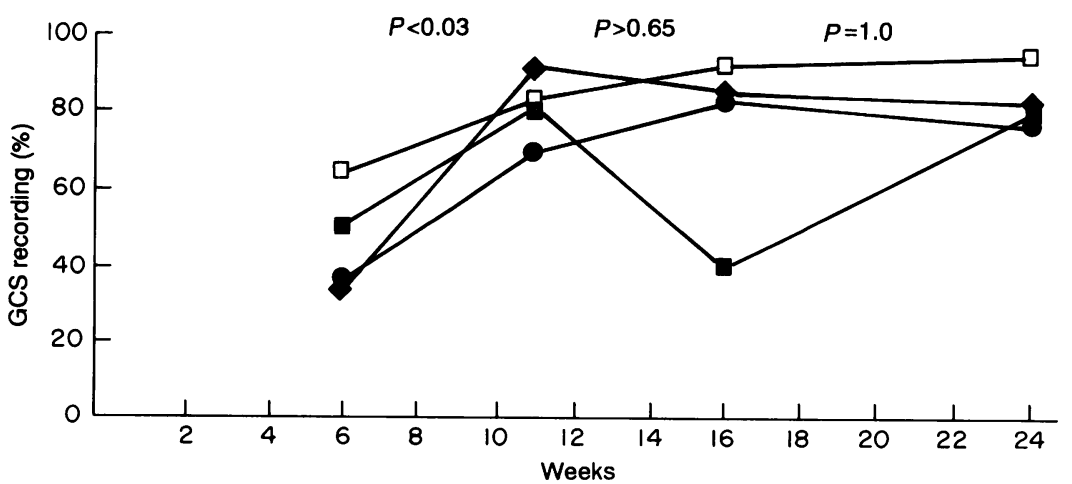

cantly after the feedback 1 . The second feedback resulted in a lesser impact on recording. Other workers have had variable results regarding the timing of feedback, Martin et al., ${ }^{9}$ showed that no feedback intervention was required for 3 months. Rhyne \& Gehlbach, ${ }^{9}$ showed that the effect of feedback tails off after 3 months. This study has shown that recordings of data can be improved and maintained in 6 months after two feedback sessions.

The individual graphs (Figs 1, 2 \& 3) show a marked variability in the response of individual SHOs initially: this variability was reduced by feedback. There were fluctuations in individual SHO performance which may have been due to circumstances outside the work environment.

Although there was no quality control group, there was little difference in the frequency of recording when comparing each week of the first 6-week audit. Secondly if the figures from individual weeks are reviewed, there is a significant increase in the frequency of recordings in the first week after feedback which was maintained in subsequent weeks. Thirdly, the SHOs were unaware of the last 4-week audit of GCS recordings and the frequency of recordings was maintained, as a result of feedback alone. The effect of feedback was different at each hospital because of variations in the effectiveness of those delivering the feedback, as well as those receiving it.

\section{CONCLUSIONS}

This study showed that audit and active feedback improves data recording. The first feedback had the greatest impact and recordings were maintained over 6 months with two feedback sessions.

\section{ACKNOWLEDGEMENTS}

The authors would like to thank Anita Hawtin at Pinderfields Hospital and the A\&E reception staff at
St James's University Hospital for help in data collection and $\mathrm{Dr}$ Adams, $\mathrm{Dr}$ Illingworth and $\mathrm{Mr}$ Zoltie for advice in writing this paper.

\section{REFERENCES}

1. Department of Health (1989) Working for Patients. HMSO, London.

2. Mitchell M.W. \& Fowkes F.G.R. (1985) Audit reviewed: does feedback on performance change clinical behaviour. Journal of the Royal College of Physicians 19, 251-254.

3. Shaw C. (1989) Medical Audit. A Hospital Handbook. The King's Fund Centre, London.

4. Wolcott B.W., Ornelas-Wilson L.A. \& Wendorf B. The morning after. Daily audit and its effects in emergency divisions at Brooke Army Medical Center. Review Bulletin, 2-5.

5. Frazier W.H. \& Brand D.A. (1979) Quality assessment and the art of medicine. The anatomy of laceration care. Medical Care 17, 480-90.

6. Linn B.S. (1980) Continuing medical education: impact on emergency room burn care. Journal of the American Medical Association 244, 565-570.

7. Gleadhill D.N.S., Thomson J.Y. \& Simms P. (1987) Can more efficient use be made of $X$-ray examinations in the accident and emergency department? British Medical Journal 294, 943-947.

8. Jelinek G.A. \& Banham N.D.G. Reducing the use of plain abdominal radiographs in an emergency department. Archives of Emergency Medicine 7, 241-245.

9. Martin A.R., Wolf M.A., Thibodeau L.A., Dzazu V. \& Braunwald E. (1980) A trial of two strategies to modify the test ordering behaviour of medical residents. New England Journal of Medicine 303, 1330-1336.

10. Rhyne R.L. \& Gehback S.H. (1979) Effects of an educational feedback strategy on physician utilisation of thyroid function panels. Journal of Family Practice 8, 1003-1007. 